\title{
Effect of uterine immunomodulation on hematobiochemical parameters in cyclic non-breeding cows
}

\author{
Saraswat Sahoo ${ }^{1}$, Debendra Narayan Mohanty ${ }^{1}$, Srinibas Das² and Arpita Padhy ${ }^{3}$
}

1. Department of Animal Reproduction, Gynaecology and Obstetrics, College of Veterinary Science and Animal Husbandry, Orissa University of Agriculture and Technology, Bhubaneswar, Odisha, India; 2. Department of Teaching Veterinary Clinical Complex, College of Veterinary Science and Animal Husbandry, Orissa University of Agriculture and Technology, Bhubaneswar, Odisha, India; 3. Department of Veterinary Microbiology, College of Veterinary Science and Animal Husbandry, Orissa University of Agriculture and Technology, Bhubaneswar, Odisha, India.

Corresponding author: Saraswat Sahoo, e-mail: saraswat.vet06@gmail.com, DNM: mohanty.dn@gmail.com, SD: dassrinibas@gmail.com, AP: dearlita123@gmail.com

Received: 09-06-2014, Revised: 04-09-2014, Accepted: 08-09-2014, Published online: 13-10-2014

doi: 10.14202/vetworld.2014.816-820. How to cite this article: Sahoo S, Mohanty DN, Das S, Padhy A (2014) Effect of uterine immunomodulation on hematobiochemical parameters in cyclic non-breeding cows, Veterinary World $7(10)$ : 816-820.

\begin{abstract}
Aim: To study the effect of uterine immunomodulation on hematobiochemical parameters and total immunoglobulin concentration in cyclic non-breeding cows.

Materials and Methods: Twenty-one repeat breeding cows around Bhubaneswar area were screened by white side test to detect and treat the endometritis and were assigned to three treatment protocols with an equal number of seven animals in each group. Cows in control group were administered with $50 \mathrm{ml}$ of normal saline while treatment Group I animals were given single intrauterine infusion of $20 \mathrm{ml}$ of fresh colostrum and treatment Group II animals received nonpathogenic Escherichia coli in $10 \mathrm{ml}$ sterile saline. The blood samples were collected from all the experimental animals, and hematobiochemical parameters and total immunoglobulin concentration were estimated.
\end{abstract}

Results: A high significant difference $(\mathrm{p}<0.01)$ was accounted in lymphocyte count of $E$. coli treated group within different days of sampling. Analysis of variance recorded a highly significant difference with neutrophil percent in $E$. coli lavaged cows. In colostrum treated group monocyte count showed a significant difference $(p<0.01)$ between 0 and $14^{\text {th }}$ day of sampling. The analysis of hematocrit values did not show any significant difference apart from the erythrocyte sedimentation rate parameter in the colostrum infused group with the highest significant $(p<0.01)$ variation being observed between $7^{\text {th }}$ and $14^{\text {th }}$ day of sampling. The analysis of aspartate amino transferase values in the colostrum lavaged cows revealed a significant difference, but that of alanine amino transferase values did not show any significant difference. Comparison of immunoglobulin values for different days in all the treatment protocol revealed a highly significant $(p<0.05)$ difference within various days of sampling.

Conclusion: In the present study, the local immunomodulation by different agents have been highlighted and which indicated potentiation of uterine immunity by different drug that might serve as a new direction of treatment to uterine diseases. The scope of research in the future should be widened by considering a larger population for validation.

Keywords: colostrum, cyclic non-breeders, hematocrit values, non-pathogenic Escherichia coli.

\section{Introduction}

In a recent past, the incidence of infertility has relatively increased with a consequent reduction of productivity of farm animals. It is accepted that bovine genital infection either specific or non-specific in nature, accounts for a large number of pregnancy failure in cows [1]. These infections alter the uterine environment resulting in impairment of sperm transport, sperm death and hostile environment to the subsequent development and maintenance of conceptus, leading to their death, there by affecting their fertility. Estimation of blood parameters can give an idea about severity of infection and thus we can check it either by use of conventional antibiotics or by non-conventional uterine immunomodulators.

Copyright: The authors. This article is an open access article licensed under the terms of the Creative Commons Attributin License (http:// creative commons.org/licenses/by/2.0) which permits unrestricted use, distribution and reproduction in any medium, provided the work is properly cited.
The aim of the study was to know the effect of uterine immunomodulation on hematobiochemical parameters and total immunoglobulin concentration in cyclic non-breeding cows.

\section{Materials and Methods \\ Ethical approval}

The approval for carrying out this study was taken from the Institutional Animal Ethics Committee.

\section{Collection of sample}

A total number of 21 repeat breeding cows were selected after meticulous screening and were randomly allotted into three groups $(n=7)$. Further, they were subjected to three treatment protocols as envisaged. Cows in control group were administered with $50 \mathrm{ml}$ of normal saline (I/U) while Group II animals received $20 \mathrm{ml}$ of fresh colostrum (I/U) and Group III animals were infused with $10 \mathrm{ml}$ of non-pathogenic Escherichia coli in sterile saline (I/U). About $15 \mathrm{ml}$ of blood was collected from all the animals on day 0,7 , 
14 and 21 of an estrus cycle. About $5 \mathrm{ml}$ of blood was kept in the anticoagulant ethylenediamine tetra-acetic acid treated vial for haematological examination, and the remaining $10 \mathrm{ml}$ was used to harvest serum. Estimation of hemoglobin (HB) concentration, total leucocyte count, differential count and hematocrit values were carried out immediately after collection as per standard technique.

HB concentration was estimated by Sahli's acid Hematin method [2]. Total erythrocyte count (TEC) was estimated by standard dilution technique using red blood cell dilution fluid [2]. The total leukocyte count was estimated by standard dilution technique using "Thomas fluid" as diluent [2]. For differential count, a thin blood smear was drawn on a grease free slide. Blood smear was air dried and then stained by diluted Leishman's stain. Hundred (100) cells were counted, and percentages of different white blood cells were estimated as per method described by Schalm [2]. The hematocrit parameters (erythrocyte sedimentation rate [ESR], packed cell volume [PCV], mean corpuscular hemoglobin $[\mathrm{MCH}]$, mean corpuscular hemoglobin concentration [MCHC]) were calculated as per standard technique as described by Schalm [2].

The activity of serum aspartate amino transferase (AST) and alanine amino transferase (ALT) were estimated by Modified International Federation of Clinical Chemistry method, using the reagent kit supplied by Crest Biosystem, a division of Coral Clinical Systems, Goa. The calculation was done as follows:

1. AST or ALT activity in $\mathrm{U} / \mathrm{L} 25^{\circ} \mathrm{C} / 30^{\circ} \mathrm{C}=\Delta \mathrm{A} / \mathrm{min}$ $\times 952$

2. AST or ALT activity in $\mathrm{U} / \mathrm{L} 37^{\circ} \mathrm{C}=\Delta \mathrm{A} / \mathrm{min} \times$ 1746.

\section{Results}

Perusal of the table showed non-significant changes in the hematological parameters like HB, TEC and total leucocyte count (TLC). The differential count values are depicted in the Table-1. Lymphocyte percent in non-pathogenic E. coli treated group animals found to be highly significant apart from the numerical changes in other treatment protocols. The neutrophil percent in the control and the non-pathogenic E. coli treated animals showed significant changes within the days of sampling. The eosinophil percent remained within the range of 4.71-8.14, 6.86-10.43 and 5.86-9.00 in normal saline, colostrum and E. coli treated cows at 0, 7, 14 and 21 day of sampling and showed non-significant change. The monocyte percent in the colostrum treated group animals registered a value of $1.43 \pm 0.20,1.14 \pm 0.26,1.00 \pm 0.00$ and $1.14 \pm 0.14$ on various days of sampling and registered significant differences within various days of sampling. The corresponding values of monocyte count in the other two treatment protocol registered non-significant changes. The present value of basophil in different treatment protocol showed a range between 0.14 and 0.28 and in E. coli treated group no basophils were detected in the blood at any stage of pre and post-medication. The PCV values in the different treatment protocols were estimated and mentioned in the table. The readings are found to be non-significant. The average ESR value $(\mathrm{mm} / \mathrm{h})$ was 0.64 in all days of sampling with no significant difference in normal saline uterine lavaged group. In colostrum treated group, the ESR value was highest $(1.07 \pm 0.13)$ on 21 st day of sampling followed by 14 th day of estimation $(0.71 \pm 0.10)$. The value was lowest on 7 th day $(0.50 \pm 0.00)$, and the pre-treatment value was $0.64 \pm 0.05$. In E. coli intra uterine infused group, no significant difference could be observed among various days of sampling, following coliform intrauterine bacterial loading. The average $\mathrm{MCH}$ and MCHC values of all the experimental groups treated with different drugs are shown in table that revealed no significant difference.

The present study also revealed that there is a significant difference in AST activity after administration of colostrum at different days of sampling. However, there is non-significant changes in AST and ALT activity in other treatment protocols.

\section{Discussion}

Perusal of table revealed no significant difference in HB concentration either between the experimental groups or between the days of sampling. Some workers were of the opinion that the values of HB in blood in normal healthy cows would be within the range of 8-15 g/dl [3]. The present finding corroborates with the observation made by Sabasthin et al., Pariza et al., and Pathan et al. [4-6]. However, Ahmad et al. [7] obtained a slightly lower value of $8.32 \pm 0.46$ in endometritic cows. Optimum levels of HB in conjunction with PCV are required for efficient transport of oxygen, as they are essential for normal health and production in cows [8]. This observation contradicts the present finding and is in confirmation with [9] in which there was no difference between HB level in fertile and non-fertile estrus of repeat breeder cows. The similar trend of non-significant difference was observed with TEC concentration which could be attributed to a non-significant effect on hematological parameters, in repeat breeding animal, studied during the present experiment. The present observations of TEC is comparable with the findings [5] in sub fertility cases of zebu cows, encompassing anestrus, repeat breeding and uterine infection. However, slightly higher values have been reported by Mondal and Paul [10] in repeat breeding [7], in endometritic cows and [6] in cyclic animals with no significant effect. The present finding also finds the support of Reddy et al. [11]. The present values for TLC were in accordance with [12] on $7^{\text {th }}, 14^{\text {th }}$ and $21^{\text {st }}$ day of post-partum with non-significant effect [11]. Obtained a similar value during the uterine lavage with normal saline, antibiotics and their combination in cows before and after treatment. 
Table-1: Mean and test of significance (F-test) of different hematobiochemical parameters in various experimental groups within days of sampling.

\begin{tabular}{|c|c|c|c|c|c|c|}
\hline \multirow[t]{2}{*}{ Parameters } & \multirow{2}{*}{$\begin{array}{l}\text { Treatment } \\
\text { protocols }\end{array}$} & \multicolumn{4}{|c|}{ Days } & \multirow[t]{2}{*}{ F value } \\
\hline & & $\mathbf{0}$ & 7 & 14 & 21 & \\
\hline \multirow[t]{3}{*}{$\mathrm{HB}(\mathrm{g} \%)$} & NS & $9.3 \pm 0.63$ & $9.38 \pm 0.59$ & $9.43 \pm 0.45$ & $9.46 \pm 0.44$ & 0.0164 \\
\hline & Colostrum & $10.14 \pm 0.55$ & $10.98 \pm 0.61$ & $10.27 \pm 0.64$ & $10.21 \pm 0.56$ & 0.4375 \\
\hline & E. coli & $11.54 \pm 1.30$ & $10.47 \pm 0.70$ & $10.42 \pm 0.64$ & $10.23 \pm 0.65$ & 0.4634 \\
\hline \multirow[t]{3}{*}{ TEC $\left(10^{6} / \mathrm{mm}^{3}\right)$} & NS & $5.13 \pm 0.45$ & $5.36 \pm 0.39$ & $5.27 \pm 0.34$ & $5.17 \pm 0.42$ & 0.06533 \\
\hline & Colostrum & $6.18 \pm 0.52$ & $6.86 \pm 0.52$ & $6.56 \pm 0.49$ & $6.48 \pm 0.50$ & 0.292 \\
\hline & E. coli & $5.73 \pm 0.98$ & $5.36 \pm 0.87$ & $5.26 \pm 0.89$ & $5.28 \pm 0.84$ & 0.0589 \\
\hline \multirow[t]{3}{*}{$\operatorname{TLC}\left(10^{3} / \mathrm{mm}^{3}\right)$} & NS & $8.84 \pm 1.28$ & $10.70 \pm 1.34$ & $10.19 \pm 1.44$ & $9.42 \pm 1.36$ & 0.3538 \\
\hline & Colostrum & $7.85 \pm 0.63$ & $9.30 \pm 0.64$ & $8.87 \pm 0.68$ & $8.71 \pm 0.63$ & 0.830 \\
\hline & E. coli & $7.90 \pm 1.44$ & $8.90 \pm 4.31$ & $8.70 \pm 1.50$ & $8.40 \pm 1.44$ & 0.0842 \\
\hline \multirow[t]{3}{*}{ Lymphocyte (\%) } & NS & $52.86 \pm 5.52$ & $51.29 \pm 4.27$ & $58.71 \pm 4.58$ & $59.28 \pm 4.47$ & 0.7336 \\
\hline & Colostrum & $52.85 \pm 5.52$ & $51.28 \pm 4.27$ & $58.71 \pm 4.58$ & $59.28 \pm 4.47$ & 0.733 \\
\hline & E. coli & $47.57 \pm 2.91^{\mathrm{ac}}$ & $34.43 \pm 3.41^{b}$ & $44.14 \pm 2.38^{a}$ & $49.00 \pm 2.30^{c}$ & $5.530 * *$ \\
\hline \multirow[t]{3}{*}{ Neutrophil (\%) } & NS & $30.28 \pm 3.30^{\mathrm{ab}}$ & $32.57 \pm 4.18^{b}$ & $27.28 \pm 4.64^{a}$ & $27.28 \pm 4.82^{\mathrm{ab}}$ & $4.616^{*}$ \\
\hline & Colostrum & $32.86 \pm 3.20$ & $36.29 \pm 4.40$ & $37.14 \pm 5.14$ & $35.14 \pm 4.08$ & 0.189 \\
\hline & E. coli & $42.43 \pm 2.28^{a}$ & $57.00 \pm 3.07^{b}$ & $48.86 \pm 2.53^{c}$ & $44.14 \pm 2.25^{a}$ & $6.512 * *$ \\
\hline \multirow[t]{3}{*}{ Eosinophil (\%) } & NS & $6.14 \pm 2.15$ & $8.14 \pm 1.93$ & $4.71 \pm 2.03$ & $4.71 \pm 2.46$ & 0.566 \\
\hline & Colostrum & $6.86 \pm 1.78$ & $10.43 \pm 4.36$ & $8.86 \pm 2.35$ & $7.71 \pm 2.24$ & 0.291 \\
\hline & E. coli & $9.00 \pm 1.30$ & $7.86 \pm 1.05$ & $6.14 \pm 0.79$ & $5.86 \pm 0.70$ & 2.216 \\
\hline \multirow[t]{3}{*}{ Monocyte (\%) } & NS & $2.14 \pm 0.40$ & $2.14 \pm 0.82$ & $2.00 \pm 0.43$ & $1.87 \pm 0.40$ & 0.062 \\
\hline & Colostrum & $1.43 \pm 0.20^{\mathrm{a}}$ & $1.14 \pm 0.26^{\mathrm{ac}}$ & $1.00 \pm 0.00^{\mathrm{bc}}$ & $1.14 \pm 0.14^{\mathrm{ab}}$ & $3.564 *$ \\
\hline & E. coli & $1.00 \pm 0.21$ & $1.00 \pm 0.00$ & $1.14 \pm 0.14$ & $1.00 \pm 0.00$ & 0.300 \\
\hline \multirow[t]{3}{*}{ Basophil (\%) } & NS & $0.14 \pm 0.14$ & $0.28 \pm 0.18$ & - & - & 1.375 \\
\hline & Colostrum & $0.28 \pm 0.18$ & $0.28 \pm 0.18$ & - & $0.14 \pm 0.14$ & 0.846 \\
\hline & E. coli & - & - & - & - & -6 \\
\hline \multirow[t]{3}{*}{ PCV } & NS & $27.71 \pm 1.56$ & $28.14 \pm 1.62$ & $28.42 \pm 1.49$ & $28.28 \pm 1.01$ & 0.045 \\
\hline & Colostrum & $30.14 \pm 1.28$ & $31.28 \pm 1.76$ & $30.14 \pm 1.51$ & $29.03 \pm 1.43$ & 0.382 \\
\hline & E. coli & $32.14 \pm 3.30$ & $32.14 \pm 3.58$ & $31.71 \pm 3.02$ & $32.14 \pm 3.13$ & 0.004 \\
\hline \multirow[t]{3}{*}{ ESR $(\mathrm{mm} / \mathrm{hr})$} & NS & $0.64 \pm 0.05$ & $0.64 \pm 0.77$ & $0.64 \pm 0.13$ & $0.64 \pm 0.03$ & 0.00 \\
\hline & Colostrum & $0.64 \pm 0.05^{a}$ & $0.5 \pm 0.07^{\mathrm{a}}$ & $0.71 \pm 0.10^{a}$ & $1.07 \pm 0.13^{b}$ & $6.619 * *$ \\
\hline & E. coli & $0.71 \pm 0.10$ & $0.57 \pm 0.07$ & $0.50 \pm 0.06$ & $0.57 \pm 0.07$ & 1.5833 \\
\hline \multirow[t]{3}{*}{$\mathrm{MCH}(\mu \mathrm{g})$} & NS & $18.38 \pm 0.68$ & $17.64 \pm 0.47$ & $17.67 \pm 0.58$ & $18.44 \pm 0.71$ & 0.499 \\
\hline & Colostrum & $16.71 \pm 0.79$ & $16.22 \pm 0.62$ & $15.85 \pm 0.69$ & $15.99 \pm 0.67$ & 0.291 \\
\hline & E. coli & $21.13 \pm 1.28$ & $21.18 \pm 1.73$ & $21.64 \pm 1.95$ & $21.09 \pm 1.77$ & 0.023 \\
\hline \multirow[t]{3}{*}{$\mathrm{MCHC}(\mathrm{g} / \mathrm{dl})$} & NS & $33.51 \pm 1.13$ & $32.78 \pm 1.59$ & $32.83 \pm 1.43$ & $33.48 \pm 1.25$ & 0.085 \\
\hline & Colostrum & $33.54 \pm 0.49$ & $35.88 \pm 0.70$ & $33.97 \pm 0.56$ & $35.27 \pm 1.07$ & 1.770 \\
\hline & E. coli & $36.03 \pm 2.18$ & $33.33 \pm 1.40$ & $33.56 \pm 1.25$ & $32.81 \pm 1.50$ & 0.770 \\
\hline \multirow[t]{3}{*}{ ALT (U/L) } & NS & $35.11 \pm 3.56$ & $34.24 \pm 3.50$ & $33.88 \pm 3.50$ & $33.54 \pm 3.42$ & 0.037 \\
\hline & Colostrum & $38.24 \pm 3.39$ & $36.61 \pm 3.34$ & $36.04 \pm 3.31$ & $35.31 \pm 3.18$ & 0.1413 \\
\hline & E. coli & $36.10 \pm 3.20$ & $35.37 \pm 3.15$ & $34.84 \pm 3.17$ & $34.51 \pm 3.14$ & 0.0476 \\
\hline \multirow[t]{3}{*}{ AST (U/L) } & NS & $131.20 \pm 2.56$ & $133.20 \pm 2.92$ & $133.67 \pm 3.97$ & $134.85 \pm 4.50$ & 0.174 \\
\hline & Colostrum & $139.55 \pm 0.87^{a}$ & $134.21 \pm 1.56^{b}$ & $132.78 \pm 1.77^{\mathrm{b}}$ & $131.21 \pm 2.31^{\mathrm{b}}$ & $4.486 * *$ \\
\hline & E. coli & $134.30 \pm 2.79$ & $134.00 \pm 3.20$ & $131.45 \pm 2.95$ & $130.57 \pm 3.08$ & 0.380 \\
\hline
\end{tabular}

HB: Hemoglobin, TEC: Total erythrocyte count, TLC: Total leucocyte count, PCV: Packed cell volume, ESR: Erythrocyte sedimentation rate, $\mathrm{MCH}$ : Mean corpuscular hemoglobin, $\mathrm{MCHC}$ : Mean corpuscular hemoglobin concentration, ALT: Alanine amino transferase, AST: Aspartate amino transferase, NS: Non-significant, E. coli: Escherichia coli, $a, b, c$, : same superscripts do not differ significantly and different superscripts differ significantly. $*$ : Significant at $5 \%$ level, $* *$ : Significant at $1 \%$ level

The lymphocyte count observed in the present study is within range (48-75) and comparable to the report of Chauhan [13]. The lymphocyte percent observed in the present study is in agreement with the findings of [7] and [6] in cyclic cows and [14] in cows having normal estrus [11]. Reported a similar value in repeat breeding cows with intra uterine lavage of normal saline on pre-treatment stage. However, they recorded a non-significantly higher value of lymphocyte percent, following treatment that corroborated the present finding of normal saline and colostrum treatment on $14^{\text {th }}$ and $21^{\text {st }}$ day.

Analysis of variance recorded a highly significant difference $(\mathrm{p}<0.01)$ in connection with neutrophil percent in E. coli lavaged cows [11]. Reported a pre and post treatment values of $34.00 \pm 1.42$ and $27.67 \pm 1.42$, $33.67 \pm 2.70$ and $30.50 \pm 2.70,34.50 \pm 2.29$ and $26.50 \pm 2.29,30.50 \pm 1.58$ and $31.17 \pm 1.58$ respectively for repeat breeding cows treated with either antibiotics uterine lavage, normal saline lavage and their combination along with control. However, they recorded a non-significantly lower value of neutrophil following normal saline lavage. The present value of Eosinophil percent in the blood corroborated the finding of $[4,11,14]$, and the aforesaid workers did not find any significant difference. Elevation of eosinophil count is marked in parasitic infestations and allergic reactions. As the selected animals were 
apparently healthy and disease free, the eosinophil count remained within a physiological limit. The present finding of monocyte value in blood is in agreement with finding of [6]. On the contrary [7,11,14,15], reported higher values of monocytes in repeat breeding cows with normal estrus and heifers. The decrease in monocyte in the blood might be due to temporary migration of monocyte to the uterine lumen, as a result of opsonization of uterine microbes. The present investigation with respect to basophil count corroborates with finding of [7] reported the value of basophil to be $0.08 \pm 0.05,0.32 \pm 0.11$ and $0.24 \pm 0.12$ in cyclic, non-cyclic and in endometritic cows respectively. Similarly [14] found no significant difference of basophil count between estrus and anestrus cows and recorded a value of $0.44 \pm 0.68$ and $0.66 \pm 0.81$ respectively in cyclic and anestrus cows.

The PCV (\%) observed in the present study is in agreement with finding of [13]. Non-significant difference of PCV value has been reported by Ahmad et al. [7] in endometritic cows [10]. Reported a value of 28.4 in repeat breeding cows [11]. Did not find any significant difference following normal saline lavage between pre- and post-treatment period. Higher value of ESR have been reported by Ahmad et al. [7] which $9.00 \pm 0.40,6.60 \pm 0.40$ and $8.29 \pm 0.42$ respectively in cyclic, non-cyclic and endometritic cows, whereas [5] recorded a very high value of ESR in repeat breeding cows $(11.1 \pm 5.6)$ against normal cyclic $(7.5 \pm 1.2)$ cows. These workers recorded the ESR value after $24 \mathrm{~h}$ of standing and the disagreement from the present observation might be due to the interval of reading that was taken after $1 \mathrm{~h}$. Many workers have reported increase in PCV and ESR values in repeat breeding and endometritic cows and inferred that it may be due to chronic subclinical uterine infections [5]. PCV and ESR values in the present study didn't show such significant alterations except colostrum treated group with respect to ESR. So, it may be presumed that the increase in ESR values at some instances might be non-specific and may not justify any valid inference.

Perusal of table did not reveal any significant variation in the average $\mathrm{MCH}$ and MCHC values of all the experimental groups treated with different drugs. This finding corroborated with the finding of [7] and [14] who reported non-significant changes in the $\mathrm{MCH}$ and MCHC values in repeat breeding cross bred heifers.

Analysis of variance revealed no significant difference with respect to ALT activity than animals with normal saline treatment. Analysis of variance also revealed a high significant $(\mathrm{p}<0.01)$ difference with respect to AST activities at different days of observation in the colostrum which followed a similar trend as that of ALT activity [16]. Reported the concentration of ALT and AST to be ranging from $11.42 \pm 2.06$ to $16.09 \pm 2.91$ and $41.32 \pm 6.18 \mathrm{RE}$ units/ml respectively in cows in and around Uttar Pradesh [17]. Estimated the concentration of ALT and AST (U/L) to be 38.1 \pm 3.7 , $36.8 \pm 2.3$ and $134.9 \pm 4.6,136.4 \pm 7.0$ respectively in fertile and repeat breeder cows [18]. Recorded a significant value $(18.45 \pm 3.05 \mathrm{U} / \mathrm{L})$ of AST in repeat breeder cow with respect to control $(11.81 \pm 1.99 \mathrm{U} / \mathrm{L})$ [19]. Reported a value of ALT and AST to be $25.17 \pm 4.19$, $17.14 \pm 2.42$ and $32.15 \pm 3.14,22.26 \pm 3.29$ respectively in normal cyclic and repeat breeding cows. The higher ALT and AST activity in repeat breeders on day of observation, which after administration of three different protocols decreased significantly, which finds the support of Pandey et al. [17]. The variability of AST enzyme in the three groups of treatment might be due to the activity of AST enzyme that catalyses the transfer of $\alpha$-amino group from the amino acid and is widely distributed in animal tissues. This variability after treatment could not substantiate the earlier observation made by Virmani et al. [20] who observed a non-significant difference following the treatment. The alteration of the ALT and AST activities in repeat breeding cows are to be stabilized through the infusion of colostrum and E. coli while normal saline infused animals showed the higher activities of AST. This finds the support of Tareen et al. [21] who concluded that mild liver damaged animals have lower mean as compared to moderate liver damaged animals and the highest mean activities are observed in cows with lowest body condition. The lowest activities of these enzymes were recorded in the animal with satisfactory body condition. Thus, it could be inferred that although there may be moderate tissue damage, but this could be associated with infertility conditions of cows under observation. Higher values of ALT and AST concentration in cows affected with endometritis have also been reported by Burke et al. [22] which is in conformity with the present finding.

\section{Conclusion}

In the present experiment, therapeutic efficacy of different intrauterine immunomodulators like normal saline, colostrum and non-pathogenic E. coli medication were studied and their effect on various hematological parameters were evaluated. The ESR value was found to be significant in colostrum treated group within various interval of sampling. Similar significant results were obtained in neutrophil count in normal saline and nonpathogenic E. coli treated groups. The AST concentration in the colostrum treated group showed a significant dipping within the days of sampling indicating the healing of the tissues. However, other hematobiochemical parameters did not show statistical significant changes, but they certainly vary numerically. The colostrum as an intra-uterine immunomodulator showed an excellent result in improving the blood picture.

\section{Authors' Contributions}

SS and DNM designed the study. SD collected and processed the samples AP drafted and revised the 
manuscript. All authors read and approved the final manuscript.

\section{Acknow ledgments}

The authors are grateful to the Department of Animal Reproduction, Gynaecology and Obstetrics for providing the financial and technical support in carrying out the research work.

\section{Competing I nterests}

The authors declare that they have no competing interests.

\section{References}

1. Sirohi, N.S., Monga, D.P. and Knar, S.K. (1989) Microbiological studies on some reproductive disorders of cattle. Indian J. Anim. Sci., 59(5): 537-541.

2. Schalm, O.W. (1965) Veterinary Haematology. $2^{\text {nd }}$ ed. Lea and Febriger, Philadelphia, USA.

3. Blood, D.C., Rodostits, C.M. and Handerson, J.A. (1989) Veterinary Medicine. 7th ed. Balliere, Tindall, London.

4. Sabasthin, A., Kumar, V.G., Nandi, S. and Murthy, V.C. (2012) Blood hematological and biochemical parameters in normal cycling, pregnant and repeat breeding buffaloes (Bubalus bubalis) maintained in isothermic and isonutritional conditions. Asian Pac. J. Reprod., 1(2): 117-119.

5. Pariza, K.F., Bari, A.S.M., Bari, F.Y., Alam, M.G.S. and Noor, M. (2009) Clinico-pathological profiles of sub-fertility in zebu cows. Bangladesh Vet., 26(1): 1-7.

6. Pathan, M.M., Das, H., Khan, J.Z., Siddiquee, G.M., Latif, A. and Parsani, H.R. (2011) Comparative studies on haemato-biochemical profile of cyclic and non-cyclic holstein-friesian cross-bred cows. Waymba J. Anim. Sci., 3: e-journal, ISSN: 2012-578X

7. Ahmad, I., Gohar, A., Ahmad, N. and Ahmad, M. (2003). Haematological profile in cyclic, non-cyclic and endometritic cross bred cattle. Int. J. Agric. Biol., 5(3): 332-334.

8. Kumar, S., Sharma, M.C. and Dwibedi, S.K. (1986). Nutrition and reproduction: Macro and micro nutrients in relation to fertility. Proceedings of the V National Congress, Guwahati, 23-30.

9. Awasthi, M.K. and Kharche, K.G. (1987). Haemoglobin concentration relation to reproduction. Indian J. Anim. Reprod., 8: 95.

10. Mondal, M.K. and Paul, S.K. (2012). Haemato-biochemical profile in repeat breeding cross bred cows. Explor. Anim. Med. Res., 2(1): 60-65.

11. Reddy, N.C.S., Bramhaiah, K.V., Naidu, K.S. and Kumar, R.V.S. (2012) Effect of uterine lavage therapy on haematological and biochemical parameters in repeat breeder cows. Therigenology Insight., 2(1): 1-6.

12. Mohanty, J.K. (2006) Local and systemic immunomodulatory effect of exogenous prostaglandin administration in normal and abnormal parturient cows. M.V.Sc. Thesis Submitted to Orissa University of Agriculture and Technology, Bhubaneswar.

13. Chauhan, R.S. (1995) Text Book of Veterinary Clinical and Laboratory Diagnosis. $1^{\text {st }}$ ed. Lordson Publishers (P) Ltd, New Delhi.

14. Singh, A.S. and Singh, O.N. (2006) Haematological studies on crossbred heifers with anestrus. Indian J. Anim. Res., 40(2): 170-172.

15. Ali, R. and Shukla, S.P. (2012) Haemato- biochemical changes in post partum anestrous buffaloes during low breeding season. Researcher., 4(9): 55-58.

16. Sharma, M.C., Kumar, P., Joshi, C. and Kaur, H. (2006) Status of serum minerals and biochemical parameters in cattle of organized farms of western Uttar Pradesh. Asian J. Anim. Vet. Adv., 1(1): 33-41.

17. Pandey, V., Singh, A.K. and Sharma, N. (2009) Blood biochemical profile in fertile and repeat breeding crossbred cows under field conditions. Vet. Pract., 10(1): 45-48.

18. Khan, K.D., Hameed, T., Kakar, M.A., Samad, H.A., Ahmad, N., Lodhi, L.A. and Qureshi, Z.I. (2005) A study on serum transaminase activities in endometritic, repeat breeder and anestrus crossbred cows. J. App. Em. Sc., 1(2): 49-53.

19. Kalita, D.J. and Sarmah, B.C. (2006) Mineral profile and serum enzyme activities of normal cycling and repeat breeding cows. Indian J. Anim. Res., 40(1): 49-51.

20. Virmani, M., Malik, R.K., Singh, P. and Dalal, S.S. (2011) Studies on blood biochemical and mineral profiles with the treatment of acyclicity in post-partum anestrus Sahiwal cows. Haryana Vet., 50: 77-79.

21. Tareen, K.D., Kakar, M.A., Qureshi, Z.I., Lodhi, L.A. and Samad, H.A. (2005) Serum transaminase activities in endometritic, repeat breeder and estrus crossbred cows. $J$. Reprod. Fertil. Dev., 17(2): 214-215.

22. Burke, C.R., Meier, S., McDougall, S., Compton, C., Mitchell, M. and Roche, J.R. (2010) Relationships between endometritis and metabolic state during the transition period in pasture-grazed dairy cows. J. Dairy Sci., 93(11): 5363-5373. 